\title{
The economic impact of a nurse practitioner-directed lung cancer screening, incidental pulmonary nodule, and tobacco-cessation clinic
}

\author{
Christopher R. Gilbert, DO, MS, FCCP, ${ }^{\mathrm{a}}$ Rob Ely, MBA, ${ }^{\mathrm{b}}$ Joelle T. Fathi, DNP, ARNP, CTTS, ${ }^{\mathrm{a}}$ \\ Brian E. Louie, MD, MPH, ${ }^{\mathrm{a}}$ Candice L. Wilshire, MD, ${ }^{\mathrm{a}}$ Hannah Modin, MPH, ${ }^{\mathrm{c}}$ Ralph W. Aye, MD, \\ Alexander S. Farivar, MD, ${ }^{a}$ Eric Vallières, $\mathrm{MD},{ }^{\mathrm{a}}$ and Jed A. Gorden, $\mathrm{MD}^{\mathrm{a}}$
}

\section{ABSTRACT}

Objective: Lung cancer screening programs have become increasingly prevalent within the United States after the National Lung Screening Trial results. We aimed to review the financial impact after programmatic implementation of Advanced Registered Nurse Practitioner-led programs of Lung Cancer Screening and Tobacco Related Diseases, Incidental Pulmonary Nodule Clinic, and Tobacco Cessation Services.

Methods: We reviewed revenue from 2013 to 2016 by our nurse practitioner-led program. Encounters were queried for charges related to outpatient evaluation and management, professional procedures, and facility charges related to both outpatient and inpatient procedures. Revenue was normalized using 2016 data tables and the national Medicare conversion factor (35.8043).

Results: Our program evaluated 694 individuals, of whom 75\% (518/694) are enrolled within the lung cancer-screening program. Overall revenue associated with the programs was $\$ 733,336$. Outpatient evaluation and management generated revenue of $\$ 168,372$. In addition, professional procedure revenue accounted for an additional $\$ 60,015$ with facility revenue adding an additional $\$ 504,949$.

Conclusions: A nurse practitioner-led program of lung cancer screening, incidental pulmonary nodules, and tobacco-cessation services can provide additional revenue opportunities for a Thoracic Surgery and Interventional Pulmonology Division, as well as a health care system. The current national, median annual wage of a nurse practitioner is $\$ 98,190$, and the cost associated directly to their salary (and benefits) may remain neutral or negative within certain programs. However, the larger economic benefit may be realized within the division and institution. This potential additional revenue appears related to evaluation of newly identified diseases and subsequent evaluations, procedures, and operations. (J Thorac Cardiovasc Surg 2018;155:416-24)

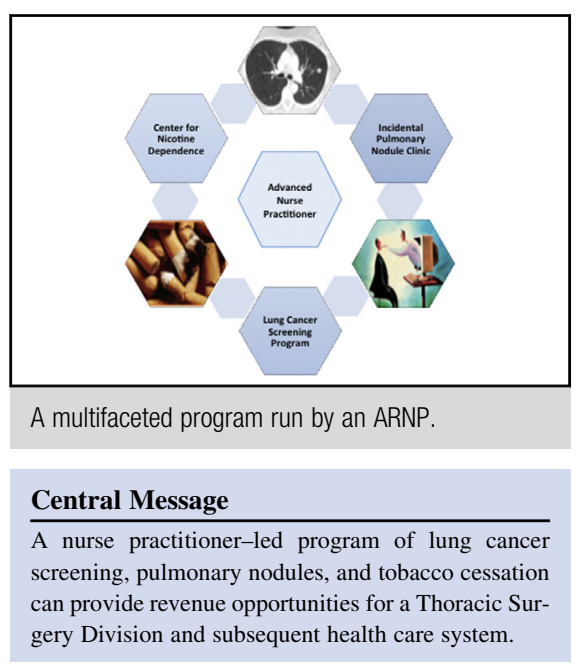

\section{Perspective}

Current guidelines for lung cancer screening offer a paucity of advice in programmatic implementation and maintenance of screening, and without addressing the economic impact of starting such a program. We report that a centralized model, run by a nurse practitioner, can provide revenue within a thoracic surgery division and overall health care system.

See Editorial Commentaries pages 425 and 426.

See Editorial page 369
From the ${ }^{\mathrm{a}}$ Division of Thoracic Surgery and Interventional Pulmonology, Swedish Cancer Institute; ${ }^{\mathrm{b}}$ Swedish Medical Center, Seattle, Wash; and ${ }^{\mathrm{c} C e n t e r}$ for Learning and Innovation, Lake Success, NY.

Support for this project was provided from The Center for Lung Research in honor of Wayne Gittinger.

Read at the 97th Annual Meeting of The American Association for Thoracic Surgery, Boston, Massachusetts, April 29-May 3, 2017.

Received for publication April 13, 2017; revisions received July 8, 2017; accepted for publication July 15, 2017; available ahead of print Oct 5, 2017.

Address for reprints: Christopher R. Gilbert, DO, MS, FCCP, Swedish Cancer Institute, 1101 Madison St, Suite 900, Seattle, WA 98104 (E-mail: christopher.gilbert@ swedish.org).

$0022-5223 / \$ 36.00$

Copyright $($ C 2017 by The American Association for Thoracic Surgery

http://dx.doi.org/10.1016/j.jtcvs.2017.07.086
The publication of the National Lung Screening Trial ${ }^{1}$ has ushered in a new era of hope for the early diagnosis and treatment of lung cancer. The use of low-dose computed tomography demonstrated a relative reduction in lung cancer mortality of $20 \%$ and reduction in overall mortality of $6.7 \%,{ }^{1}$ a feat not accomplished in other

Scanning this QR code will take you to an online data supplement. To view the AATS 2016 Webcast, see the URL next to the webcast thumbnail.

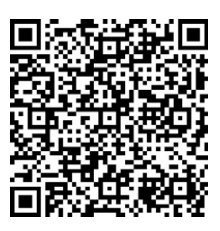




\section{Abbreviations and Acronyms \\ ARNP $=$ Advanced Registered Nurse Practitioner \\ CMS $=$ Centers for Medicare \& Medicaid Services \\ $\mathrm{CPT}=$ Current Procedural Terminology \\ DRG = Diagnosis-Related Group \\ $\mathrm{E} \& \mathrm{M}=$ Evaluation and Management \\ $\mathrm{EMR}=$ Electronic Medical Record \\ LCSP $=$ Lung Cancer Screening Program \\ $\mathrm{RVU}=$ Relative Value Units}

Cancer Institute is part of Swedish Medical Center, which is a nonprofit, tertiary referral facility located in Seattle, Washington. A mixture of both privately employed physicians and hospital-employed physicians practice medicine within the outpatient and inpatient facilities of the hospital system.

A clinical database of all patients enrolled within the program was cross-referenced with billing records and the Electronic Medical Record (EMR) from the same time frame to identify participants. The Institutional Review Board at Swedish Medical Center (Institutional Review Board\# 6008S-16) approved this study, and a waiver of consent was granted. Data were collected and stored in a REDCap database. ${ }^{14}$ Simple descriptive statistics were used to report revenue characteristics, and all revenue is reported in United States dollars (\$).

\section{Program Description}

The program exists within the combined Division of Thoracic Surgery and Interventional Pulmonology with an ARNP as the main provider of outpatient clinical care, professional billing, and administrative management of the program. The ARNP is independently licensed to practice medicine in the State of Washington, has received additional training in tobacco treatment (Certified Tobacco Treatment Specialist), and currently employed within the division at 1.0 full-time equivalent. Our program (and subsequent clinics) is managed by the ARNP with oversight from a medical (interventional pulmonologist) and surgical (general thoracic surgeon) director.

Referrals for any of the 3 programs occurred through our EMR for patients within our system or faxed paper format for those outside our system. After a referral was received, patients were scheduled for an initial visit with the ARNP. For those patients referred for lung cancer screening, a scheduler called the patient to review eligibility criteria, ${ }^{15}$ and if all screening criteria were met, a Shared Decision-Making encounter with the ARNP was scheduled. Patients who were referred for smoking cessation/counseling or incidental pulmonary nodules were immediately scheduled for a visit with the ARNP.

During the initial office visit, if the history was consistent with current or former tobacco abuse, a tobacco-related diseases comprehensive review of systems was obtained with an emphasis on detection of signs or symptoms of respiratory disorders, vascular complications, cardiac disease, and tobacco-related malignancies. This was followed by a comprehensive head-to-toe physical examination, including carotid, oropharynx, cardiac, respiratory, abdominal, and lower-extremity examination. Discovery of clinically concerning findings relevant to thoracic surgery was managed within the screening program with appropriate referrals to the supervising specialties. Nonthoracic clinical and radiographic findings were managed by patient counseling of both the severity and the acuity of findings, followed by communication with referral back to their primary care provider for continuity of care and directed follow-up.

\section{Data Collection and Financial Impact Determination}

Encounters were queried for charges related to outpatient Evaluation and Management (E\&M) codes, professional fees for procedures (Current Procedural Terminology [CPT]), and facility charges related to procedures/ operations (Diagnosis-Related Group [DRG] and Ambulatory Payment Classification). Relative Value Units (RVUs) associated with encounters were abstracted when appropriate. Billable data were collected, and revenue subsequently calculated using the Centers for Medicare \& Medicaid Services (CMS) 2016 data tables. ${ }^{16}$ Estimated Medicare revenue for $\mathrm{E} \& \mathrm{M}$ and physician procedural revenue were calculated by applying RVUs against the 2016 national conversion factor (35.8043). ${ }^{17}$ All revenue associated with an ARNP was adjusted at $85 \%,{ }^{18}$ per CMS guidelines. Facility revenue related to inpatient DRGs was calculated using the DRG weights from the final rule multiplied by the national operating and capital standard federal payment rates. ${ }^{19}$ Ambulatory revenue was calculated

\section{MATERIALS AND METHODS}

A retrospective review of all patients initially evaluated within the Lung Cancer Screening, Incidental Pulmonary Nodule Clinic, and Tobacco Cessation Services from 2013 to 2016 was performed. The 


\begin{tabular}{|c|c|}
\hline $\begin{array}{c}\text { Current Procedural } \\
\text { Terminology Code }\end{array}$ & Code Description \\
\hline 99202 & PR OFFICE OUTPATIENT NEW 20 MINUTES \\
\hline 99203 & PR OFFICE OUTPATIENT NEW 30 MINUTES \\
\hline 99204 & PR OFFICE OUTPATIENT NEW 45 MINUTES \\
\hline 99205 & PR OFFICE OUTPATIENT NEW 60 MINUTES \\
\hline 99211 & PR OFFICE OUTPATIENT VISIT 5 MINUTES \\
\hline 99212 & PR OFFICE OUTPATIENT VISIT 10 MINUTES \\
\hline 99213 & PR OFFICE OUTPATIENT VISIT 15 MINUTES \\
\hline 99214 & PR OFFICE OUTPATIENT VISIT 25 MINUTES \\
\hline 99215 & PR OFFICE OUTPATIENT VISIT 40 MINUTES \\
\hline 99401 & PREVENT COUNSEL,INDIV,15 MIN \\
\hline 99402 & PREVENT COUNSEL,INDIV,30 MIN \\
\hline 99403 & PREVENT COUNSEL,INDIV,45 MIN \\
\hline 99404 & PREVENT COUNSEL,INDIV,60 MIN \\
\hline 99406 & TOBACCO USE CESSATION INTERMEDIATE 3-10 MINUTES \\
\hline 99407 & TOBACCO USE CESSATION INTENSIVE >10 MINUTES \\
\hline 99441 & PR PHYS/OHP TELEPHONE EVALUATION 5-10 MIN \\
\hline 99442 & PR PHYS/QHP TELEPHONE EVALUATION 11-20 MIN \\
\hline 99443 & PR PHYS/QHP TELEPHONE EVALUATION 21-30 MIN \\
\hline G0296 & COUNSELING VISIT TO DETERM LDCT ELIG \\
\hline G0436 & TOBACCO-USE COUNSEL 3-10MIN \\
\hline 60437 & TOBACCO-USE COUNSEL>1OMIN \\
\hline & \\
\hline
\end{tabular}

FIGURE 1. List of CPT codes used during outpatient office visit by the advanced nurse practitioner. These CPT codes were used to collect direct patient revenue from professional billing.

using the Outpatient Prospective Payment System payment by rate from the Health care Common Procedure Coding System code table. ${ }^{20}$

All revenue directly related to encounters within the program was reviewed. Direct revenue was defined as all professional billing directly submitted by the ARNP (Figure 1). Indirect revenue was defined as billing that occurred within our EMR and medical system that appeared directly as a result of the ARNP visit/recommendation after a visit within the program (Figure 2). Indirect revenue was identified as subsequent physician referrals $(E \& M)$, as well as additional testing and procedures (CPT, DRG, and ambulatory payment classification revenue) from these referrals.

\section{RESULTS}

A total of 694 individuals were identified in the programs from 2013 to 2016. The overwhelming majority of individuals $(75 \%, 518 / 694)$ were enrolled within the LCSP and still actively receiving follow-up within the program $(77 \%, 531 / 694)$. Individual within the program referral/ enrollment resulted from the following sources: primary care $(78 \%)$, self-referral $(10 \%)$, nonthoracic surgery specialists $(6 \%)$, thoracic surgery $(5 \%)$, and other/unknown $(1 \%)$. Overall gross revenue associated with the program over this 3-year timeframe was $\$ 733,336$ after allowing for correction using the CMS national conversion factor (Figure 3). The gross revenue associated with the Division of Thoracic Surgery and Interventional Pulmonology itself was $\$ 681,503$, accounting for $92.9 \%$ of the identified charges.

The gross direct revenue associated with ARNP encounters accounted for $\$ 149,655$, corresponding to the production of 4917.4 RVUs. This direct revenue was solely produced through outpatient $\mathrm{E} \& \mathrm{M}$ encounters with the ARNP (Figure 1), using new patient $(99,202-99,205)$ visits (54\%), established patient $(99,211-99,215)$ visits $(41 \%)$, preventative counseling $(99,401-99,404)$ codes $(2 \%)$,

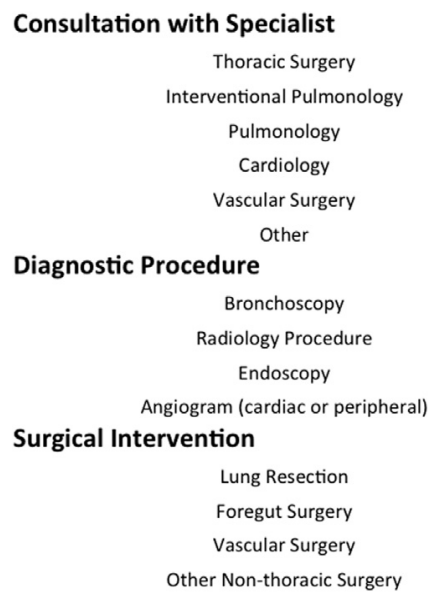

FIGURE 2. List of potential sources of indirect revenue as a result of the advanced nurse practitioner visit within our program.

tobacco counseling $(99,406-99,407$, G0436-G0437) codes $(<1 \%)$, lung cancer screening shared decision-making (G0296) visits (2\%), and telephone evaluation (9944199443) codes $(<1 \%)$. No procedures or inpatient billing from the ARNP accounted for revenue within the program.

Within the program population, we identified 216 patients $(31 \%)$ with at least 1 pulmonary nodule $6 \mathrm{~mm}$ or greater $(167$ patients in LCSP and 49 patients in the incidental pulmonary nodule clinic), with 142 patients $(20 \%)$ having nodules greater than $8 \mathrm{~mm}$ (113 in LCSP and 29 in the incidental pulmonary nodule clinic). Within this population, 48 patients (8 patients from the incidental pulmonary nodule program and 40 patients from the LCSP, for a total of $7 \%$ of our program population) underwent 75 procedures/operations (bronchoscopy, 11; transthoracic needle aspiration, 16; lung resection, 19; endoscopy, 13; foregut surgery, 9; nonthoracic surgery, 7) for abnormal imaging or newly identified disease. This resulted in a total indirect revenue associated with the program of $\$ 583,681$. The largest portion $(87 \%$ or $\$ 504,949$ ) of this was related to facility fees brought into the institution from procedures/operations, followed by professional physician fees (CPT) related to procedural revenue $(10 \%$ or $\$ 60,015)$ and $\mathrm{E} \& \mathrm{M}$ visits for consultations $(3 \%$ or $\$ 18,717)$ (Figure 3 ).

Within the Division of Thoracic Surgery and Interventional Pulmonology itself, the outpatient clinic revenue was $\$ 167,816$, with the majority of this outpatient clinic revenue related to ARNP billing. The overall amount of outpatient revenue remains a smaller proportion of the total revenue; however, this patient volume represents an increasing trend in the number of patients enrolled within the programs over the study timeframe (Figure 4).

\section{DISCUSSION}

We identified that an ARNP-led tobacco-related diseases program incorporating lung cancer screening, incidental 
Thoracic Surgery

Total (Thoracic and Non-Thoracic)

\begin{tabular}{|c|c|c|c|c|}
\hline Revenue Type & $\begin{array}{c}\text { Relative } \\
\text { Value Units }\end{array}$ & $\begin{array}{l}\text { Estimate Medicare } \\
\text { Reimbursement }^{\star}\end{array}$ & $\begin{array}{c}\text { Relative } \\
\text { Value Units }\end{array}$ & $\begin{array}{l}\text { Estimated Medicare } \\
\text { Reimbursement }{ }^{*}\end{array}$ \\
\hline Inpatient Hospital Revenue (DRG) & & $\$ 402,526$ & & $\$ 432,419$ \\
\hline Ambulatory Procedure Revenue (APC) & & $\$ 53,627$ & & $\$ 72,530$ \\
\hline Physician Procedures (CPT) & 1606.91 & $\$ 57,534$ & 1676.19 & $\$ 60,015$ \\
\hline $\begin{array}{l}\text { Outpatient Evaluation and Management } \\
\text { - Consulting Physicians }\end{array}$ & 507.23 & $\$ 18,161$ & 522.76 & $\$ 18,717$ \\
\hline $\begin{array}{l}\text { Outpatient Evaluation and Management } \\
\text { - ARNP* }\end{array}$ & 4917.41 & $\$ 149,655$ & 4917.41 & $\$ 149,655$ \\
\hline 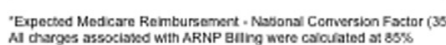 & & $\$ 681,503$ & & $\$ 733,336$ \\
\hline
\end{tabular}

FIGURE 3. Total gross revenue associated with programs from 2013 to 2016 . Additional analysis provided for overall revenue as well as overall from Thoracic Surgery and Interventional Pulmonology Division only.

pulmonary nodules, and tobacco-cessation services can provide additional revenue opportunities for a Thoracic Surgery and Interventional Pulmonology Division, as well as a health care system. Recommendations for lung cancer screening currently exist ${ }^{6}$; however, the actual programmatic development and implementation remain variable, likely related to biases and resources available within different institutions and health care settings. Other models have been described, including the use of a nurse navigator, ${ }^{21,22}$ as well as an automated, structured reporting system that provides an optional or direct referral to a pulmonologist with any suspicious findings. ${ }^{11,23,24}$ There are likely theoretic and institutional-level pros and cons to these approaches, but the financial impact of implementing these various programs within a health care system or subspecialty practice has not been previously reported.

Numerous questions regarding lung cancer screening and the implementation of successful (from a clinical, research, and financial standpoint) programs remain. Certain programmatic requirements require fulfillment to receive recognition as LCSP (and therefore likely qualification for reimbursement from insurers), and currently, many subspecialties remain involved in the care of patients with tobacco-related diseases. Elements paramount to successful lung cancer screening, such as shared decision making, are not required of other cancer screening methods and therefore make the process of lung cancer screening more specialized and onerous, an important task that many physicians may not have the appropriate time or training. ${ }^{25}$ The current structure of LCSP programs remains unclear, both in what currently exists now and in what may be the best program setup. An advanced practice clinician is likely, or can be well trained, to fill the role of leading such a program, not only for lung cancer screening but also for an impactful role in tobaccocessation counseling and treatment. ${ }^{26,27}$ In addition, advantages of a centralized, ARNP-based model may include a single location for the delivery of care, regularly available consultation with specialists, and the ability to dedicate the job focus solely to this program (potentially in aspects of clinical care, research development/implementation, and fiscal responsibility). The ability to have a central person/program coordinating the evaluation of imaging abnormalities, follow-up, and tobacco counseling may help improve coordination of care and ultimate patient outcomes, although data to support such a statement remain unavailable.

One of the limitations of our revenue assessment includes the use of "indirect" or "downstream" sources and cost calculations. However, on the basis of the analysis of our study population, the majority of revenue generated appears to be "indirect" or "downstream," related to facility charges from the institution. This figure has often been difficult to calculate, but has been reported in other facets of thoracic oncology, including the benefits demonstrated by having an endobronchial ultrasound program. ${ }^{28}$ This downstream revenue source likely remains the largest financial impact from programs such as this, and because it will not be realized directly in a single clinics bottom line, it must be recognized and appropriately used by providers attempting to negotiate for resources to establish such programs. At face value, when comparing our ARNP billing revenue over a 3-year timeframe with the median salary of an ARNP $\left(\$ 98,190\right.$ base salary, ${ }^{29} \$ 145,321$ with 


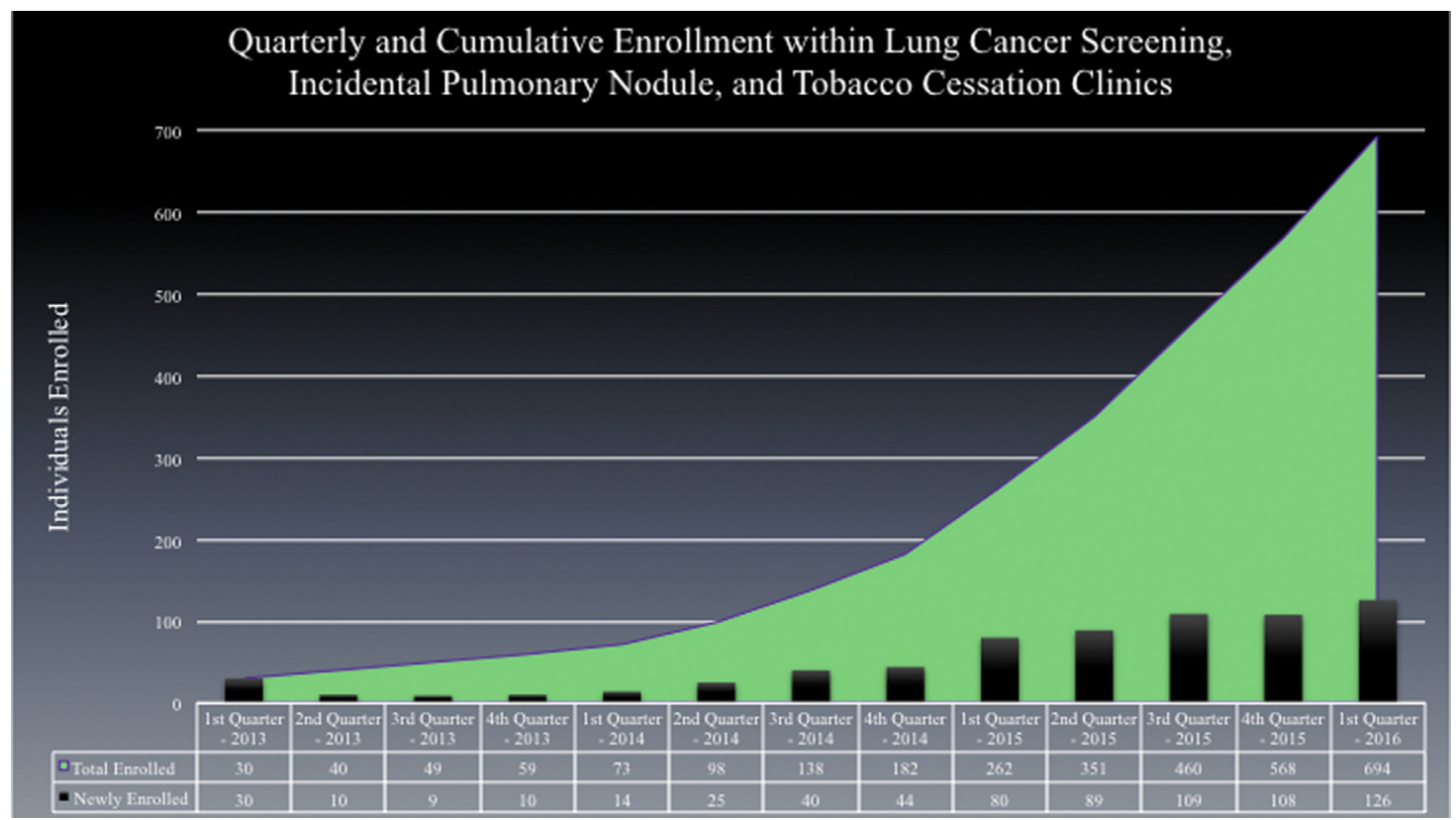

FIGURE 4. Quarterly and cumulative enrollment within lung cancer screening, incidental pulmonary nodule, and tobacco-cessation clinics.

benefits ${ }^{30}$ ) over this same 3 -year timeframe, a clear negative financial impact will be seen. It is also important to note that the revenue reported here reflects the first 3 years of establishment of our LCSP. We recognize that with additional individual/patient accrual into the programs (as demonstrated in Figure 4), the ARNP may eventually represent a positive financial impact within the division itself on face value, as often occurs in other disciplines. ${ }^{26,31-33}$

\section{Study Limitations}

The revenue associated with programs such as this may be difficult to calculate. Because this was a retrospective study, we may have missed encounters; however, a strength of our study is our use of the electronic billing system and medical record, allowing for the likely capture of all submitted billing within our clinic system. Because patients cannot be seen within the clinic without an electronic visit and an electronic billing submission (even if it would be a no charge visit), our records of direct revenue should be approximately $100 \%$. We elected to not capture revenue associated with radiographic imaging, which could account for a significant downstream revenue stream, especially knowing that patients with positive lung cancer screening results (Lung RADS 3 and 4) will almost certainly be obtaining additional scans directly related to the program. In addition, the approval of CPT code G0297 by CMS allows for low-dose computed tomography billing, but is largely due to the institution or radiology. We elected to not include this CPT because it mainly is a radiology code, and its approval only came as of January 2016, almost at the end or our queried period. Our decision to exclude radiographic testing was based on the difficulty of linking radiographic testing within our system to providers and particular indications, a potential weakness of our study design/health care system. Encounters regarding the use of neoadjuvant therapy, adjuvant therapy, or surveillance for lung cancer were not captured. However, although missing encounters and potential revenue (particularly from radiology) remains a limitation, this would likely only underestimate our overall generated revenue for this study.

Another major limitation of our description remains the generalizability of our program. Our program uses an independently practicing ARNP as the operational and clinical lead in these clinics; however, this key component in our program may not be feasible in other health care settings. An ARNP is currently used at 1.0 full-time equivalent to the program(s). A significant amount of nonbillable time is spent in administrative duties such as outreach/education programs and programmatic development, as well as nonreimbursable clinical duties such as updating clinical databases and ensuring appropriate patient recall. This continued dedication to the appropriate development of the program(s), even with low overall reimbursement (especially as noted during the initial portion of the program), may seem fiscally irresponsible; however, as a division we have believed this programmatic dedication and development were crucial to its long-term success.

Current practice laws and licensing for advanced practice clinicians remain highly variable not only between states but also between provider types. ${ }^{26,32,34,35}$ Within the State of Washington (and 22 additional states), ARNPs have significant autonomy, ${ }^{36}$ but this is not reflected within a 
number of other states in the nation. ${ }^{34,37}$ In Washington, an ARNP functions with independent practice and prescriptive authority. They provide diagnosis and treatment of illnesses, retain personal and professional responsibility for any act that constitutes the practice of medicine, and bill for professional services provided. This is different than the practice authority of Physician Assistants in Washington, who can only practice medicine under the authority of a supervising physician, with a delegation agreement in place.

An additional limitation may be our combination of interventional pulmonary and thoracic surgery within the same division and workspace, subspecialties commonly divided and at times competing between medical and surgical departments in many other institutions. Another limitation may be our decision as a division to use the same provider as the referral contact for both lung cancer screening and incidental pulmonary nodule evaluations (mainly radiographic evaluation and follow-up imaging). Because of some similarities in lung cancer screening and incidental pulmonary nodule evaluations (mainly radiographic evaluation and follow-up imaging), many aspects of the care can be fairly similar, including the evaluation of risk, need for counseling as to what having a nodule means, and a program for appropriate and timely follow-up imaging.

Our study remains a single-center study, and its generalizability remains unknown because various factors, including clinical time, facility, database management, and reimbursement may all play key factors in the development and success of such a program elsewhere. The significant differences that programs may have, such as reimbursement differences by region, overhead costs of operating a practice related to regional differences, and practice size/composition, prompted us to not perform a detailed cost analysis, but rather provide somewhat generalizable production and revenue data that other groups/facilities may attempt to use when planning for the establishment of similar programs. Numerous stakeholders, including hospital administration and finance, radiology, thoracic surgery, medical oncology, radiation oncology, pulmonary medicine, and primary care physicians, must all be interested in participating in programs like this for them to be successful. Local referral patterns and institutional reputation may influence the successful establishment and longitudinal sustainability of such programs.

\section{CONCLUSIONS}

We present the first study to date describing the potential financial impact of an ARNP-led program related to Lung Cancer Screening, Incidental Pulmonary Nodules, and Tobacco Cessation Counseling and Treatment Services (Online Data Supplement). We are able to demonstrate that with the use a centralized system using an ARNP, the revenue obtained from direct patient contact within the office appears to be a fiscally feasible option. The additional revenue generated from subsequent procedures and operations within the division seems positive, and the additional revenue generated within the health care system seems even more beneficial. This desire for financial responsibility must be continuously weighed against the overall benefits of patient care and the scientific evidence supporting LCSP. The institution of programs such as these may provide high-quality care, meeting the needs of an often marginalized population, while also offering a potential positive impact to the health care system and health benefit to their patients. Further study is needed to identify the cost factors and potential efforts to improve cost-effective care models for care.

\section{Webcast}

You can watch a Webcast of this AATS meeting presentation by going to: https://aats.blob.core.windows.net/media/ 17AM/2017-05-02/RM302-304/05-02-17_Room302-304_ 1418_Gilbert.mp4.

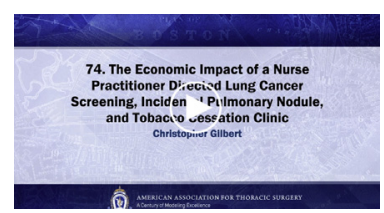

\section{Conflict of Interest Statement}

Authors have nothing to disclose with regard to commercial support.

\section{References}

1. National Lung Screening Trial Research Team, Aberle DR, Adams AM, Berg CD, Black WC, Clapp JD, Fagerstrom RM, et al. Reduced lung-cancer mortality with low-dose computed tomographic screening. N Engl J Med. 2011;365 395-409.

2. Fontana RS, Sanderson DR, Woolner LB, Taylor WF, Miller WE, Muhm JR Lung cancer screening: the Mayo Program. J Occup Med. 1986;28:746-50.

3. Infante M. Long-term follow-up results of the DANTE Trial, a randomized study of lung cancer screening with spiral computed tomography. Am J Respir Crit Care Med. 2015;191:1166-75.

4. Melamed MR, Flehinger BJ, Zaman MB, Heelan RT, Perchick WA, Martini N. Screening for early lung cancer: results of the Memorial Sloan-Kettering Study in New York. Chest. 1984;86:44-53.

5. Wood DE. National Comprehensive Cancer Network (NCCN) Clinical Practice Guidelines for Lung Cancer Screening. Thorac Surg Clin. 2015;25:185-97.

6. Wiener RS, Gould MK, Arenberg DA, Au DH, Fennig K, Lamb CR, et al. An Official American Thoracic Society/American College of Chest Physicians Policy Statement: implementation of low-dose computed tomography lung cancer screening programs in clinical practice. Am J Respir Crit Care Med. 2015;192 881-91.

7. Centers for Medicare \& Medicaid Services. Decision memo for screening for lung cancer with low dose computed tomography $(L D C T)(C A G-00439 N)$. Available at: https://www.cms.gov/medicare-coverage-database/details/nca-decisionmemo.aspx $?$ NCAId $=274 \&$ NcaName $=$ Screening + for + Lung + Cancer + with + Low + Dose + Computed + Tomography $+($ LDCT $) \&$ MEDCACId $=68 \&$ IsPopup $=$ $\mathrm{y} \& \mathrm{bc}=\mathrm{AAAAAAAAAgAAAA} \% 3 \mathrm{~d} \% 3 \mathrm{~d} \&$. Accessed March 9, 2016.

8. U.S. Preventive Services Task Force, Moyer VA. Screening for Lung Cancer: U.S. Preventive Services Task Force Recommendation Statement. Ann Intern Med. 2014;160:330-8. 
9. Gillaspie EA, Allen MS. Computed tomographic screening for lung cancer: the Mayo Clinic experience. Thorac Surg Clin. 2015;25:121-7.

10. Lanni TB, Stevens C, Farah M, Boyer A, Davis J, Welsh R, et al. Early results from the implementation of a lung cancer screening program: the Beaumont Health System Experience. Am J Clin Oncol. December 8, 2015 [Epub ahead of print].

11. Walker BL, Williamson C, Regis SM, McKee AB, D’Agostino RS, Hesketh PJ, et al. Surgical outcomes in a large, clinical, low-dose computed tomographic lung cancer screening program. Ann Thorac Surg. 2015;100:1218-23.

12. Patel S, Cho A, Lamont A, Klatt-Ellis T. Implementing a community hospital lung cancer screening program: a multidisciplinary program and a standardized reporting system. Am Coll Radiol. 2014;11:527-30.

13. Korst RJ. Systematic approach to the management of the newly found nodule on screening computed tomography: role of dedicated pulmonary nodule clinics. Thorac Surg Clin. 2013;23:141-52.

14. Harris PA, Taylor R, Thielke R, Payne J, Gonzalez N, Conde JG. Research electronic data capture (REDCap)-a metadata-driven methodology and workflow process for providing translational research informatics support. J Biomed Inform. 2009;42:377-81.

15. Centers for Medicare \& Medicaid Services. National Coverage Determination (NCD) for lung cancer screening with low dose computed tomography (LDCT) (210.14). In: Department of Health and Human Services, ed. Available at: http://www.cms.gov. Accessed November 13, 2016.

16. Center for Medicare \& Medicaid Services. National Physician Fee Schedule Relative Value File Calendar Year 2016. In: CMS, ed. Available at: http:// www.cms.gov. Accessed December 16, 2016.

17. American Medical Association. Medicare RBRVS Physicians' Guide \& CMS Correction Notices. Available at: https://www.ama-assn.org/medicare-rbrvsphysicians \%E2\%80\%99-guide-cms-correction-notices. Accessed November $13,2016$.

18. Centers for Medicare \& Medicaid Services. Medicare Information for Advanced Practice Registered Nurses, Anesthesiologist Assistants, and Physician Assistants. In: Department of Health and Human Services, ed. Available at: http:// www.cms.gov. Accessed January 15, 2015.

19. Center for Medicare \& Medicaid Services. Details for title: FY 2016 Final Rule, Correction Notice and Consolidated Appropriations Act of 2016 Tables. Available at: http://www.cms.gov. Accessed December 16, 2016.

20. Center for Medicare \& Medicaid Services. Hospital Outpatient Prospective Payment System: Addendum B: January 2016 update. Available at: http://www.cms. gov. Accessed December 16, 2016.

21. Miller DL, Mayfield WR, Luu TD, Helms GA, Muster AR, Beckler VJ, et al. Community-based multidisciplinary computed tomography screening program improves lung cancer survival. Ann Thorac Surg. 2016;101:1864-9.

22. Miller AT, Kruger P, Conner K, Robertson T, Rowley B, Sause W, et al. Initial outcomes of a lung cancer screening program in an integrated community health system. J Am Coll Radiol. 2016;13:733-7.

23. Mazzone P. The rationale for, and design of, a lung cancer screening program. Cleve Clin J Med. 2012;79:337-45.

24. The International Early Lung Cancer Action Program Investigators, Henschke CI, Yankelevitz DF, Libby DM, Pasmantier MW, Smith JP, Miettinen OS. Survival of patients with stage I lung cancer detected on CT screening. N Engl J Med. 2006;355:1763-71.

25. Tanoue LT, Tanner NT, Gould MK, Silvestri GA. Lung cancer screening. Am J Respir Crit Care Med. 2015;191:19-33.

26. Center for Practice Improvement \& Innovation. Hiring a physician assistant or nurse practitioner. Available at: http://www.acponline.org/running_practice/. Accessed November 13, 2016.

27. Kilpatrick K, Kaasalainen S, Donald F, Reid K, Carter N, Bryant-Lukosius D, et al. The effectiveness and cost-effectiveness of clinical nurse specialists in outpatient roles: a systematic review. J Eval Clin Pract. 2014;20:1106-23.

28. Pastis NJ, Simkovich S, Silvestri GA. Understanding the economic impact of introducing a new procedure: calculating downstream revenue of endobronchial ultrasound with transbronchial needle aspiration as a model. Chest. 2012;141:506-12.

29. US Department of Labor. Occupational Employment and Wages, May 2015: 29-1171 Nurse Practitioners. [webpage] 2015 March 30, 2016. Available at: http://www.bls.gov/oes/current/oes291171.htm. Accessed October 12, 2016.

30. US Department of Labor. Employer costs for employee compensation-March 2017. In: Bureau of Labor Statistics, ed; 2017.

31. Bookbinder M, Glajchen M, McHugh M, Higgins P, Budis J, Solomon N, et al. Nurse practitioner-based models of specialist palliative care at home: sustainability and evaluation of feasibility. J Pain Symptom Manage. 2011;41:25-34.
32. Medical Group Management Association. NPP utilization in the future of US Healthcare: an MGMA research \& analysis report. Available at: http://www. mgma.com/. Accessed November 13, 2016.

33. Counts MM, Mayolo R. Growing revenue with APNs. Nurs Manage. 2007;38: 49-50.

34. Phillips SJ. 28th Annual APRN legislative update: advancements continue for APRN. Nurs Pract. 2016;41:21-48.

35. American College of Physicians. Internists and Physician Assistants: Team Based Primary Care: A Policy Monograph of the American Academy of Physician Assistants and the American College of Physicians. Philadelphia, PA: American College of Physicians; 2009.

36. Washington State Legislature. WAC Title, Chapter 840, Section 300, ARNP scope of practice. In: Legislature WS, ed. 8/17/16 ed. legs.wa.gov; 2016.

37. American Association of Nurse Practitioners. State Practice Environment. April 14, 2016. Available at: https://www.aanp.org/legislation-regulation/statelegislation/state-practice-environment. Accessed November 13, 2016.

Key Words: advanced registered practitioner, finance/ revenue, incidental pulmonary nodule, lung cancer screening, tobacco-related diseases

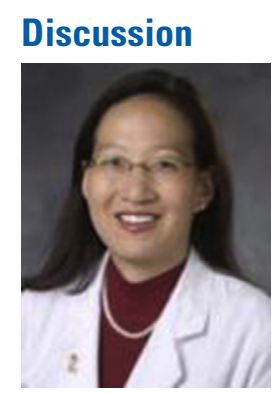

Dr B. Tong (Durham, NC). Dr Gilbert, congratulations on a great study and for building a program that achieves what I believe CMS has intended for screening to be done in terms of the face-to-face or decision-making and tobacco-cessation counseling. As I mentioned on Sunday morning, I believe that lung cancer screening should have a structured and programmatic approach as yours and not be a drivethrough service. That being said, there is significant commitment and investment required of our institutions to provide this. I congratulate you for demonstrating that in addition to being the right thing to do for patients who are at risk from a preventative health and maintenance standpoint, it can actually bring value to the organization. I have a few questions about your program and study approach.

First is regarding the ARNP. So doing the math, with a total of 694 patients seen during the 3-year period, if you break that down, it is approximately 230 patients per year and 4 to 5 patients being seen per week. With a full full-time equivalent rate, what does that person do when he/she is not screening patients or seeing patients with nodules?

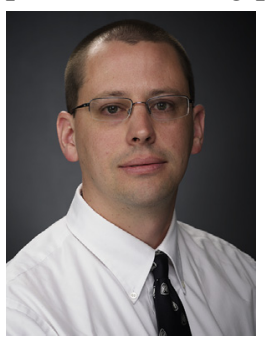

Dr Gilbert (Seattle, Wash). Since the program has started, her only role was to run the program.

Dr Tong. How did you garner support for that?

Dr Gilbert. I was not there for the beginning so I can't take credit for a lot of this, but the real impetus was to create a program that would work for our division and the patients, and it was set aside that that would be her only 
job. She runs all 3 of those programs. She spent a lot of time in the beginning going out talking to people, trying to let people know what we are doing, what is available. We serve a fairly decently large geographic area, and so she spent a number of days not on site but elsewhere giving talks, doing things like that.

As you could see from the one side, our enrollment has significantly ramped up, so she has had less time to do that, but in the beginning her main job was really to build this program; that is what she spent all of her time doing.

Dr Tong. You mentioned that you did not account for the lung RADS 3 and 4A findings where there would be an interval imaging study in terms of your indirect revenue, is that correct?

Dr Gilbert. The radiology studies, yes.

Dr Tong. So that was not part of your calculations, is that correct?

Dr Gilbert. That's correct.

Dr Tong. Why not include that?

Dr Gilbert. When we talked to our financial person, it was a bit difficult trying to figure out which would definitely be directly due to our program versus not, and so we just elected to not follow any of the radiographic imaging.

Dr Tong. I suspect that is going to add to your bottom line.

Dr Gilbert. I suspect it would too. Some of those other things that we didn't capture probably would as well, but you are correct.

Dr Tong. In your article, you also listed sources of indirect revenue to include consultation with cardiology, vascular surgery, and others. Do you have defined triggers for cardiology or vascular surgery referral based on the low-dose computed tomography findings or were these based on history and symptoms only?

Dr Gilbert. They are based on history and symptoms.

Dr Tong. Relating to the generalizability of your screening findings and therefore the downstream results, was the proportion of positive and concerning findings consistent with those reported in the literature, that is, approximately $10 \%$ lung RADS 3 and 4 and $1.5 \%$ to $2 \%$ lung cancer findings?

Dr Gilbert. I am not sure I have that data per se. What I can say from another project that we did is that our lung cancer rate was in the $4 \%$ range.

Dr Tong. That's about double what it is in the literature.

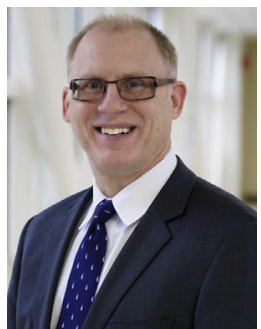

Dr T. Demmy (Buffalo, NY). This is interesting because it seems like such an individual could be the glue that binds together potentially competitive services such as interventional pulmonary and thoracic surgery and could be flexible in their duties to cover patients if other midlevel surgery practitioners are sick or assisting in operations. So tell me, how do you use this individual to practically collaborate with the referrals? At what times in your clinics do you have interventional pulmonary or surgery providers? Is interventional pulmonary part of your thoracic surgery division or is it a separate entity? Overall, how does this nurse improves communication?

Dr Gilbert. I'm an interventional pulmonologist; 10 of us are in the same office. So the thoracic surgeons, interventional pulmonologists, and ARNPs are all in the same office. We routinely are available ready in regard to consultations. The majority of these patients, particularly in the lung cancer screening program, end up being presented at our multidisciplinary tumor board, which is attended by all those same folks. The harder part would likely be some of the outside consultation use, but that oftentimes goes through the primary care doctor as well.

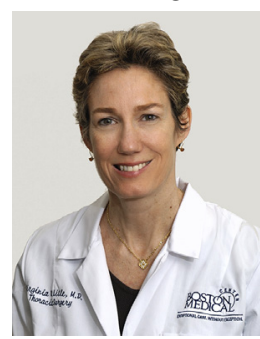

Dr V. Litle (Boston, Mass). In our lung cancer screening program at Boston Medical Center, we calculate that we are only screening approximately $10 \%$ of potentially eligible patients, so I would like to know what percent you think you are capturing, and assuming it is similarly low what you are going to do to try to increase that.

Dr Gilbert. I'm sorry, could you repeat the question?

Dr Litle. We only capture approximately $10 \%$ of potentially eligible patients into our lung screening program, and we are trying to identify how we are going to get the primary care providers to refer them. So do you know what percent of potentially eligible patients you are screening, and if it is similarly low, how you are going to increase that.

Dr Gilbert. How are you defining your 10\% only?

Dr Litle. We are estimating that there are a lot more smokers out there and people in the right age range who aren't coming and being referred for screening by the primary care providers from the community health centers.

Dr Gilbert. I don't know that we have looked at that specifically. I know we have tried to, but it has been hard to define in regard to what the actual denominator is. We have found in regard to the patients who are referred for lung cancer screening, probably a little more than half meet criteria, and then of those, about half do end up getting screened then. The hardest part for us, which I think is what you are referring to, is defining the denominator as to who actually would be eligible or not. I don't know that I have that number for you.

Dr Litle. Does your lung nodule clinic also take referrals from folks who come to the emergency department?

Dr Gilbert. Yes. So that might be why the $4 \%$ cancer rate is a bit higher, because that number includes the incidental pulmonary nodules as well. 


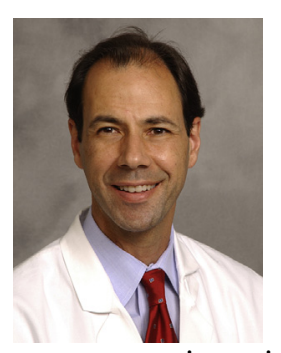

Dr T. D'Amico (Durham, NC). To address Dr Litle's question, we all could create an index of the number of patients who we operate on who meet screening criteria who were screened versus those who meet screening criteria who didn't get screened, and that should obviously increase over time, right, the percentage of people who we operate on who actually got screened, because in our center, most of the people who we operate on meet the screening criteria and didn't get screened.

Dr Litle. What is it at Duke, though, once they were potential eligible? How many do you think are out there? You can't really count the operations, but there must be a greater population.

Dr D'Amico. Betty, do you remember what it is now?

Dr Tong. Probably about $10 \%$.

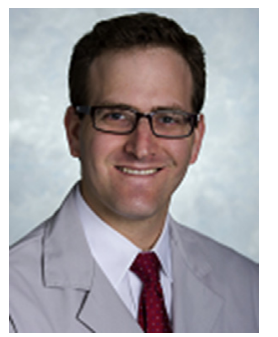

Dr S. Krantz (Evanston, Ill). I enjoyed this. My question is for the Nurse Practitioner who runs it. Where does that in terms of an expense line actually come out of? Is it within your group and division or does the hospital cover that or maybe the money flows back and forth so easily it is not separated? The reason I ask is because she charges $\$ 98,000$ a year, and in terms of professional fee billing and her professional fee, that was over 3 years; it doesn't quite pay for it; on the hospital side, it more than pays for it.

The struggle in our institution we come up with is, who pays for that? If it comes out of thoracic or pulmonary, it doesn't quite pay for itself pulmonary-wise and it pays for itself on the hospital side. Where money flows back and forth, it is not necessarily that easy to convince the hospital administrators to pay for it out of that $\$ 500,000$ that comes in the hospital revenue. So I was curious how you have that set up.
Dr Gilbert. She is employed in our clinic, so she is in the Cancer Institute under our division. To try to answer some of your questions, they are probably above my pay grade and I am not privy to some of them. What I can tell you from things that I have heard is that part of the benefit to hiring some of the ANRPs is that it frees up the surgeons to see more patients and perform more surgeries. Apparently, that has been realized on the other side. If your institution is open to that or not is difficult to know.

Part of the reason for doing this, too, is to give people some information they can take back to wherever they are to see if this may be a feasible model for them. It may not be a feasible model for many people, but it may be a feasible model for some.

Dr D'Amico. Just briefly, your advanced practice provider did the shared decision-making?

Dr Gilbert. Yes.

Dr D'Amico. Do you use a reflux screening tool? You didn't have 9 paraesophageal hernias, right?

Dr Gilbert. Dr Louie may have more information on this question, Dr Louie?

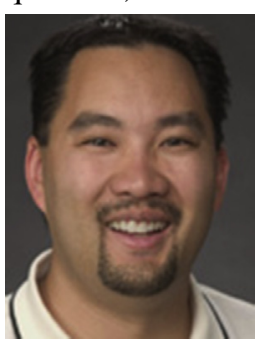

Dr B. Louie (Seattle, Wash). I can answer that. Before she took over the lung cancer screening role, she was our clinical ARNP, and so we trained her well in terms of patients with foregut disease, so she is adept at doing that. She was also a primary care provider for years before that, so she had a lot of clinical experience. After spending 3 years with us just doing clinical work, she learned quickly and was seeing primary patients with foregut disease in the clinic, so that was an easy adaptation for her. She knows what the Gastroesophageal Reflux Disease-Health Related Quality of Life is, she knows what questions to ask, and she is actually better than some of our primary care physicians at diagnosing reflux. 